\title{
Risk Stratification of Paediatric Sports Injuries Seen at a Tertiary Hospital
}

Pei Zhen Seah, ${ }^{1}{ }_{M B B S}$ (S'pore), Jade Nicolette ZH Chee, ${ }^{2}$ MBBS (S'pore), PGDSM (IOC), MMed (FM) (S'pore), Jasmine XY Feng, ${ }_{B S C \text { (Nursing), }}$ Yu Shan Ting, ${ }_{B M e d, M D}{ }^{1}$ (Aus), DCH (Aus), Shu-Ling Chong, ${ }^{1,3}{ }_{M B B S}\left(S^{\prime} p o r e\right), M R C P C H$ (UK), MPH (US)

\begin{abstract}
Introduction: In this study, we described paediatric sports injuries seen in the paediatric emergency department of a large, tertiary paediatric hospital in Singapore and evaluated risk factors for severe sports injuries.

Methods: This is a retrospective review of a paediatric trauma surveillance registry from February 2012 to October 2017, including patient demographics, type of sports, circumstances, type of injuries, and clinical management in the hospital. Patients 5 to 17 years old with a sports-related injury were included. We performed logistic regression to identify predictors of severe sports injuries (defined by Injury Severity Score of $\geq 9$ ), injuries requiring hospitalisation, trauma team activation, resuscitation, or those that resulted in death.

Results: Among 10,951 patients analysed, the most common injuries sustained were fractures $(4,819,44.0 \%)$, sprains and contusions $(3,334,30.4 \%)$. For patients with severe injuries, the median length of hospital stay was 2 days (IQR 1-3 days), and time away from sports was 162 days (IQR 104-182 days). Predictors for severe injuries include transportation by emergency medical service (aOR 6.346, 95\% CI 5.147-7.823), involvement in rugby (aOR 2.067, 95\% CI 1.446-2.957), neurological injuries (aOR 4.585, 95\% CI 2.393-4.365), dislocations (aOR 2.779, 95\% CI 1.744-4.427), fractures (aOR 1.438, 95\% CI 1.039-1.990), injuries to the head and neck (aOR 2.274, 95\% CI 1.184-4.365), and injuries to the abdomen and pelvis (aOR 5.273, 95\% CI 3.225-8.623).

Conclusion: Predictors for severe sports injuries identified may aid in risk stratification and resource allocation.
\end{abstract}

Ann Acad Med Singap 2020;49:955-62

Keywords: Emergency medicine, epidemiology, fractures, sports medicine

\section{Introduction}

Participation in competitive youth sports is on the rise due to the "catch them young" philosophy, which aims to maximise the numerous physical, social, emotional and psychological benefits associated with an active lifestyle. ${ }^{1-3}$ In the US, $69.1 \%$ of children 6-12 years old participated in at least 1 day of sporting activities in a year. ${ }^{4}$ Data show that at least 70\% of Singaporeans aged 13-19 years participate frequently and regularly in sports.,

This rising trend across the globe has seen sports injuries become an important contributor to morbidity in the paediatric age group. A 10-year Australian-based population cohort study found the overall annual incidence of child sports injury-related hospitalisation rate to be approximately 280 per 100,000 population, with an estimated total treatment cost of AUD396 million over the same period. ${ }^{7}$ A recent study in the US also showed that almost one-third of all hospital admissions in the school-going age group are due to sports injuries. ${ }^{8}$

Existing paediatric sports injury epidemiology literature is mainly from the West, with an obvious knowledge gap for corresponding injuries in Asia. ${ }^{9}$

\footnotetext{
${ }^{1}$ Department of Emergency Medicine, KK Women's and Children's Hospital, Singapore

${ }^{2}$ Department of Family Medicine, SingHealth Polyclinics, Singapore

${ }^{3}$ Duke-NUS Medical School, Singapore

Address for Correspondence: Dr Shu-Ling Chong, Department of Children's Emergency, KK Women's and Children's Hospital, 100 Bukit Timah Road, Singapore 229899.

E-mail: chong.shu-ling@kkh.com.sg
} 
Important differences exist between the type of sports commonly played in Asia and the West, as well as the sports that frequently result in injuries. Western literature shows that cross-country running, soccer and baseball had the highest injury incidence rates for boys, while cross-country running, softball and gymnastics are the highest for girls. ${ }^{10-13}$ In Asia, sports commonly played include judo, ${ }^{14}$ taekwondo ${ }^{15}$ and sepak takraw. ${ }^{16}$ Injuries reported occur mainly from cycling, basketball and soccer. ${ }^{17,18}$

Children (aged 5-12) are more likely to sustain upper limb injuries, whereas teenagers (aged 13-17) are more likely to get injured in the chest, hips/pelvis and spinal area. ${ }^{19}$ Across all age groups, the lower extremities were the most commonly injured, specifically the paediatric knee. ${ }^{20}$ Sport injuries described in the paediatric population include physeal injuries, ${ }^{21}$ overuse injuries, ${ }^{22,23}$ and heat injuries. ${ }^{24}$

The primary aim of our study is to describe the epidemiology of sports injuries sustained by schoolgoing children who presented to the paediatric emergency department (ED) of a large, Asian tertiary paediatric hospital. Our secondary aim is to evaluate the risk factors for severe paediatric sports injuries, which is defined as an Injury Severity Score (ISS) $\geq 9$; injuries requiring hospitalisation; trauma team activation; resuscitation; or injuries that resulted in death.

\section{Methods}

A retrospective chart review of patients aged 5-17 years who presented to the ED between February 2012 and October 2017 with sports injuries was conducted.

Data were extracted from the electronic medical records of KK Women's and Children's Hospital ED visits, the trauma surveillance registry, as well as inpatient records and clinic appointments related to the injury sustained. Our hospital collects prospective trauma data using the trauma registry, which is part of the National Trauma Unit in Singapore. When an injured child presents to the ED, the emergency physician is required to enter mandatory electronic fields on the circumstances of injury. Data pertaining to patient demographics, the nature of the injury (accidental versus non-accidental), blunt versus penetrating trauma, mechanism of injury (falls, motor vehicle related, sports, etc.), object(s) involved in the injury and the location of the injury are entered into this surveillance registry. The severity, location and diagnosis of the specific injuries are also documented. For this study, we extracted data relevant to patient demographics, the type of sports involved, circumstances, severity of the injuries and clinical management in the hospital. The data is then managed by an accredited trauma coordinator. When more than 1 injury was sustained in a single child, we recorded each injury separately.

Patients were divided into 2 groups for data analysis: children (aged 5-12) and teenagers (aged 13-17). We chose this dichotomy with the understanding that children and teenagers have different patterns of injury. ${ }^{8}$ Teenagers have higher rates of competitive sports involvement, and consequently, are at risk of more severe injuries. ${ }^{25}$

Injury types were classified into 6 categories: fractures, dislocations, contusions or sprains and strains, superficial, neurological, and head and spinal injuries. Analysis of the injured body part was divided into 7 regions: head and neck, face, chest, upper limbs, lower limbs, abdominal and pelvic, and back or spine injuries. Data on the mode of transport to ED-emergency medical service (EMS), non-emergency private ambulance, own transport-were also analysed.

The disposition of patients after their ED consultation (discharged with or without follow-up appointment as hospital/private clinic reviews, admitted to general ward, high-dependency unit [HDU] or intensive-care unit [ICU]), was reviewed. We defined severe injuries as an ISS of $\geq 9$, injuries requiring hospitalisation, trauma team activation, resuscitation, or those that resulted in death.

Statistical analysis was performed using SPSS Statistics version 26 (IBM Corp, Armonk, US). Pearson chi-square test was used to test associations for categorical variables; and either the Mann-Whitney $U$ test or the Student t-test was used to analyse continuous variables, depending on normality. $P$ values of $<0.05$ were considered to be statistically significant. Variables that had statistical significance at the univariable analysis were entered into the multivariable analysis. We performed a multivariable logistic regression predicting for severe injuries (as defined above) and presented point estimates using unadjusted and adjusted odds ratios (aOR), together with their 95\% confidence intervals (CI).

\section{Results}

A total of 10,951 children and teenagers were included for the analysis (Fig. 1). Among these, 5,476 (50.0\%) were in the 13-17 age group. There were no statistically significant gender differences between the 2 age groups ( $P=0.344)$.

There were 673 teenagers $(12.3 \%)$ in the $13-17$ age group transported to ED via EMS, compared to 323 $(5.9 \%)$ children in the $5-12$ age group $(P<0.001)$ (Table 1). Soccer was the most common sport resulting 


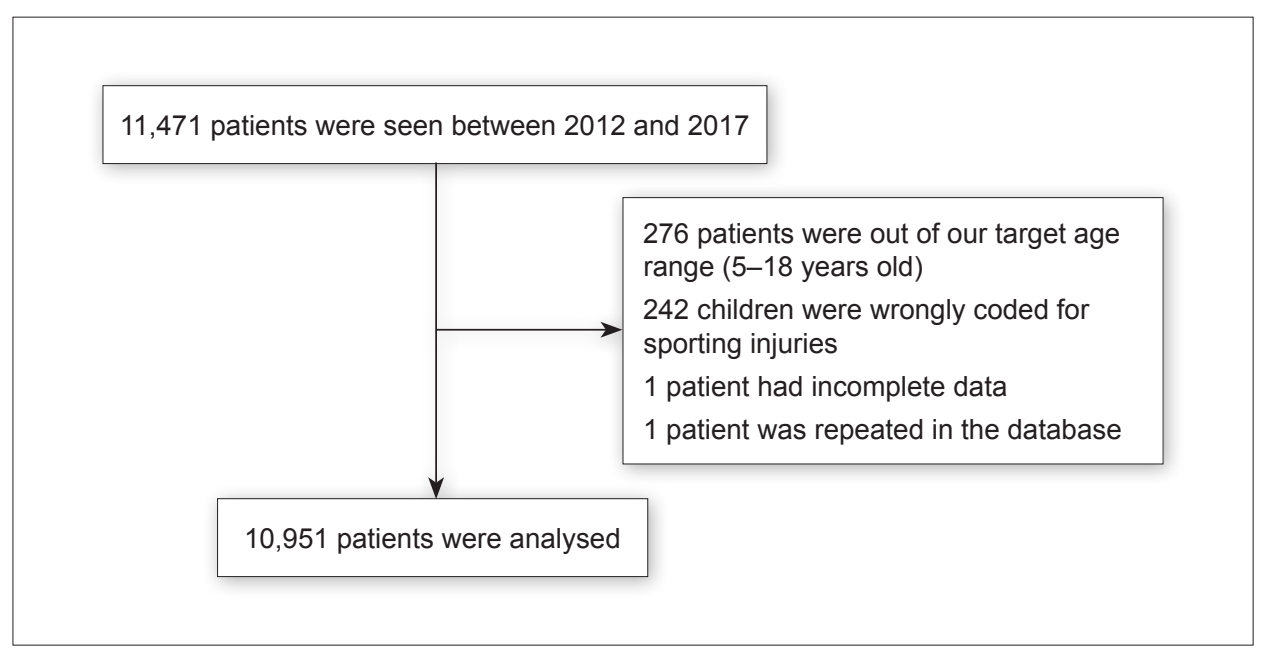

Fig. 1. Flowchart of patients analysed.

in injuries across both groups, followed by basketball and rugby (Table 1). A total of 200 children and teenagers $(1.8 \%)$ were managed in the resuscitation room.

Fractures accounted for the greatest number of ED presentations across both age groups (5-12 years [44.7\%], 13-17 years [43.3\%]). Dislocations were more common in the teenagers $(245,4.5 \%)$ compared to the children $(49,0.9 \%)(P<0.001)$. Upper limb injuries accounted for the majority of injuries in both age groups (5-12 years [39.3\%], $13-17$ years [38.6\%], $[P=0.481]$ ). Following this, the next most prevalent site of injury was the lower limbs (Table 1). A large proportion of children and teenagers with fractures to the upper and lower limbs were managed with manipulation and reduction, followed by cast application in the ED and then sent home on the same day $(4,433 / 4,585,96.7 \%)$.

Most children and teenagers $(10,459,95.5 \%)$ were discharged following ED consultation. We admitted 492 children and teenagers to the general ward $(4.5 \%)$ and only 5 to HDU or ICU. There was 1 death.

Predictors of severe injury included transportation by EMS (aOR 6.346, 95\% CI 5.147-7.823, $P<0.001$ ), involvement in rugby (aOR 2.067, 95\% CI 1.446-2.957, $P<0.001$ ), neurological injuries (aOR 4.585, 95\% CI 2.393-8.787, $P<0.001$ ), dislocations (aOR 2.779, 95\% CI 1.744-4.427, $P<0.001$ ), fractures (aOR 1.438, 95\% CI 1.039-1.990, $P=0.028$ ), injuries to the head and neck (aOR 2.274, 95\% CI 1.184-4.365, $P=0.014$ ), and abdomen and pelvis (aOR 5.273, 95\% CI 3.225-8.623, $P<0.001)$. Upper and lower injuries, while common, appeared to be at lower risk for severe injury (Table 2).

Of the 31 children and teenagers with ISS $\geq 9,19$ $(63.3 \%)$ presented with femur fractures, and 7 (23.3\%) sustained head and spinal injuries (Table 3). Thirteen children and teenagers $(41.9 \%)$ were injured while playing soccer. Five of them were admitted to HDU or ICU for observation or postoperative care (Table 4). The child who died presented to the emergency department after a soccer goal post fell on him resulting in severe traumatic brain injury.

\section{Discussion}

In this study, we described the sports injury epidemiology among school-going children and teenagers. Boys are more commonly injured, with soccer most often associated with injuries. Fractures and soft tissue injuries were common clinical diagnoses, while limb injuries were more frequent than head and neck or truncal injuries. Predictors for severe injuries were transportation by EMS, involvement in rugby, neurological injuries, dislocation, fractures, injuries to the head, neck, abdomen or pelvis.

Teenagers are larger in size, heavier, faster and stronger, and tend to have more severe contact injuries. ${ }^{26}$ They may train for longer hours and at higher intensities as they specialise further in their sport. Teenagers are more likely to be involved in competitive situations with risk-taking behaviour. ${ }^{27}$ In our study, age was no longer significant after accounting for the type of sport, mode of conveyance, type of injury and body location of injury. We report a comparable proportion of children and teenagers who self-conveyed to ED compared with being transported by EMS; ${ }^{28}$ we also highlight that patients brought in by EMS tend to have more severe injuries. In most cases, EMS is called for when the child is suspected to have more severe injuries or is nonambulatory, and this explains its predictive value for severe sports injuries. 
Table 1. Clinical presentation and descriptive data for all injuries

\begin{tabular}{|c|c|c|c|}
\hline & $\begin{array}{c}\text { Ages 5-12 } \\
(n=5475)\end{array}$ & $\begin{array}{c}\text { Ages 13-17 } \\
(\mathrm{n}=\mathbf{5 4 7 6})\end{array}$ & $P$ value \\
\hline Male, n (\%) & $3971(72.5)$ & $4016(73.3)$ & 0.344 \\
\hline Mode of arrival, $\mathrm{n}(\%)$ & & & $<0.001$ \\
\hline Own transport & $5139(93.9)$ & $4773(87.2)$ & \\
\hline Emergency medical service & $323(5.9)$ & $673(12.3)$ & \\
\hline Non-emergency private ambulance & $12(0.2)$ & $29(0.5)$ & \\
\hline Others & $1(0)$ & $1(0)$ & \\
\hline Attended in resuscitation room, $\mathrm{n}(\%)$ & $64(1.2)$ & $136(2.5)$ & $<0.001$ \\
\hline Type of sports, n (\%) & & & $<0.001$ \\
\hline Soccer & $1098(20.1)$ & $1007(18.4)$ & \\
\hline Basketball & $371(6.8)$ & $446(8.1)$ & \\
\hline Rugby & $99(1.8)$ & $259(4.7)$ & \\
\hline Others $^{a}$ & $3907(71.4)$ & $3764(68.7)$ & \\
\hline \multicolumn{4}{|l|}{ Type of injuries, n (\%) } \\
\hline Fractures & $2449(44.7)$ & $2370(43.3)$ & 0.128 \\
\hline Dislocation & $49(0.9)$ & $245(4.5)$ & $<0.001$ \\
\hline Contusions/sprains/strains & $1590(29.0)$ & $1744(31.8)$ & 0.001 \\
\hline Superficial injuries (open wound, bleeding) & $424(7.7)$ & $317(5.8)$ & $<0.001$ \\
\hline Neurological injuries & $329(6.0)$ & $278(5.1)$ & 0.033 \\
\hline Head and spinal injuries & $2(0)$ & $5(0.1)$ & 0.453 \\
\hline \multicolumn{4}{|l|}{ Location of injuries, $\mathrm{n}(\%)$} \\
\hline Head and neck & $358(6.5)$ & $339(6.2)$ & 0.457 \\
\hline Face & $496(9.1)$ & $374(6.8)$ & $<0.001$ \\
\hline Chest & $164(3.0)$ & $124(2.3)$ & 0.017 \\
\hline Upper limb & $2150(39.3)$ & $2114(38.6)$ & 0.481 \\
\hline Lower limb & $1721(31.4)$ & $2089(38.1)$ & $<0.001$ \\
\hline Abdominal/pelvic injury & $255(4.7)$ & $201(3.7)$ & 0.010 \\
\hline Back and spine & $330(6.0)$ & $264(4.8)$ & 0.005 \\
\hline Computed tomography scan done, $\mathrm{n}(\%)$ & $13(0.2)$ & $24(0.4)$ & 0.099 \\
\hline
\end{tabular}

a Other sports included athletics, badminton, cycling, floorball, netball and softball

The top 3 sports resulting in injuries were soccer, basketball and rugby. This is consistent with findings from a study by Darrow et al., which reported that soccer posed the highest rate of sports-related injuries in the paediatric population, as well as the highest rate of severe injuries. ${ }^{11,29,30}$ Soccer is a popular sport among Singaporean teens, and the long duration of contact during game play could contribute to the risk of injury. 5,6
Although injuries from soccer were common, rugby was a predictor of severe injury. Rugby, being a fullbody contact sport, can result in more severe injuries from tackling, ruck and a high incidence of foul play, ${ }^{31-34}$ when compared to soccer, which as a partial contact sport, potentially results in milder injuries in players. ${ }^{35}$

We report similar injury characteristics from other published literature. ${ }^{36,37}$ Fractures accounted for the 
Table 2. Unadjusted and adjusted logistic regression studying the predictors of severe injuries

\begin{tabular}{|c|c|c|c|c|}
\hline & $\begin{array}{l}\text { Unadjusted OR } \\
(95 \% \mathrm{CI})\end{array}$ & $P$ value & $\begin{array}{l}\text { Adjusted OR } \\
\text { (95\% CI) }\end{array}$ & $P$ value \\
\hline Male & $\begin{array}{c}1.081 \\
(0.898-1.301)\end{array}$ & 0.412 & & \\
\hline Aged $13-17$ years & $\begin{array}{c}1.363 \\
(1.157-1.605)\end{array}$ & $<0.001$ & $\begin{array}{c}1.176 \\
(0.976-1.417)\end{array}$ & 0.087 \\
\hline Soccer & $\begin{array}{c}0.829 \\
(0.667-1.030)\end{array}$ & 0.090 & & \\
\hline Rugby & $\begin{array}{c}3.222 \\
(2.388-4.347)\end{array}$ & $<0.001$ & $\begin{array}{c}2.067 \\
(1.446-2.957)\end{array}$ & $<0.001$ \\
\hline Transported by emergency medical service (EMS) & $\begin{array}{c}6.887 \\
(5.754-8.244)\end{array}$ & $<0.001$ & $\begin{array}{c}6.346 \\
(5.147-7.823)\end{array}$ & $<0.001$ \\
\hline \multicolumn{5}{|l|}{ Type of injury } \\
\hline Fractures & $\begin{array}{c}0.523 \\
(0.438-0.624)\end{array}$ & $<0.001$ & $\begin{array}{c}1.438 \\
(1.039-1.990)\end{array}$ & 0.028 \\
\hline Dislocation & $\begin{array}{c}2.570 \\
(1.809-3.649)\end{array}$ & $<0.001$ & $\begin{array}{c}2.779 \\
(1.744-4.427)\end{array}$ & $<0.001$ \\
\hline Contusions, sprains and strains & $\begin{array}{c}0.627 \\
(0.516-0.761)\end{array}$ & $<0.001$ & $\begin{array}{c}0.957 \\
(0.716-1.279)\end{array}$ & 0.765 \\
\hline Superficial injuries (open wound, bleeding) & $\begin{array}{c}1.195 \\
(0.884-1.616)\end{array}$ & 0.247 & & \\
\hline Neurological injuries & $\begin{array}{c}11.727 \\
(9.647-14.256)\end{array}$ & $<0.001$ & $\begin{array}{c}4.585 \\
(2.393-8.787)\end{array}$ & $<0.001$ \\
\hline \multicolumn{5}{|l|}{ Body region affected } \\
\hline Face & $\begin{array}{c}0.971 \\
(0.717-1.314)\end{array}$ & 0.848 & & \\
\hline Chest & $\begin{array}{c}3.528 \\
(2.559-4.865)\end{array}$ & $<0.001$ & $\begin{array}{c}0.936 \\
(0.404-2.170)\end{array}$ & 0.878 \\
\hline Upper limbs & $\begin{array}{c}0.343 \\
(0.279-0.421)\end{array}$ & $<0.001$ & $\begin{array}{c}0.397 \\
(0.275-0.574)\end{array}$ & $<0.001$ \\
\hline Lower limbs & $\begin{array}{c}0.494 \\
(0.406-0.601)\end{array}$ & $<0.001$ & $\begin{array}{c}0.547 \\
(0.398-0.752)\end{array}$ & $<0.001$ \\
\hline Abdomen and pelvis & $\begin{array}{c}4.336 \\
(3.376-5.569)\end{array}$ & $<0.001$ & $\begin{array}{c}5.273 \\
(3.225-8.623)\end{array}$ & $<0.001$ \\
\hline Back and spine & $\begin{array}{c}1.966 \\
(1.485-2.601)\end{array}$ & $<0.001$ & $\begin{array}{c}0.717 \\
(0.389-1.322)\end{array}$ & 0.287 \\
\hline
\end{tabular}

CI: confidence interval; OR: odds ratio

majority of ED presentations in both the younger and older age groups. This echoes the findings by Taylor and Attia that fractures were the most frequently evaluated paediatric injuries in the emergency department. ${ }^{36}$ Femur fractures in particular have been reported to be associated with readmissions to the hospital and requiring further interventions if they require surgical management. ${ }^{37}$ While contusions, sprains and strains accounted for many ED visits in our population, they tend to be milder injuries. This is similar to reports from Hong Kong and South Korea, where low-energy injuries such as superficial injuries, strains and sprains were the most common type of injuries. ${ }^{17,38}$ 
Table 3. Further analysis of children with an Injury Severity Score (ISS) $\geq 9$

Total number $(\mathrm{n}=31)$

\begin{tabular}{|c|c|}
\hline \multicolumn{2}{|l|}{ Tier, n (\%) } \\
\hline Tier 1 (ISS score >15) & $2(6.5)$ \\
\hline Tier 2 (ISS score 9-15) & $29(93.5)$ \\
\hline \multicolumn{2}{|l|}{ Type of injuries, n (\%) } \\
\hline Femur fractures & $19(63.3)$ \\
\hline Head and spinal injuries & $7(23.3)$ \\
\hline \multicolumn{2}{|l|}{ Type of sports, n (\%) } \\
\hline Soccer & $13(41.9)$ \\
\hline Outdoor running & $2(6.5)$ \\
\hline Rugby & $2(6.5)$ \\
\hline Trampoline & $2(6.5)$ \\
\hline Wushu & $2(6.5)$ \\
\hline Others $^{\mathrm{a}}$ & $10(32.3)$ \\
\hline Median length of hospital stay, days (IQR) & $2(1-3)$ \\
\hline Admission into high dependency unit/intensive care unit, n (\%) & $5(16.1)$ \\
\hline Median number of days away from sports, days (IQR) & $162(104-182)$ \\
\hline
\end{tabular}

IQR: interquartile range

${ }^{\text {a }}$ Other type of sports include trampoline, rugby, wushu, cycling and parkour.

Table 4. Patients admitted to intensive care unit (ICU) and high dependency unit (HDU)

\begin{tabular}{clccl}
\hline $\begin{array}{c}\text { Patient } \\
\text { no. }\end{array}$ & Sports/mechanism & $\begin{array}{c}\text { ICU stay } \\
\text { (days) }\end{array}$ & $\begin{array}{c}\text { HDU stay } \\
\text { (days) }\end{array}$ & Injury and reasons for ICU or HDU admission \\
\hline 1 & Cycling/fall & 5 & 17 & Pancreatic laceration/ postoperative care \\
\hline 2 & Go-Kart/collision & 3 & 4 & Splenic laceration/ postoperative care \\
\hline 3 & Parkour/fall & 0 & 11 & $\begin{array}{l}\text { L1/L2 compression fracture and bilateral calcaneal fractures/ } \\
\text { postoperative care }\end{array}$ \\
\hline 4 & Rugby/collision & 0 & 6 & Rib fracture and renal laceration/observation \\
5 & Soccer/fall & 0 & 2 & Skull vault fracture/observation
\end{tabular}

Injuries to the abdomen and pelvis were associated with severe injury. These patients were likely to require hospitalisation to monitor for visceral injury and evolving haemodynamic compromise. In our study population, however, few injured children and teenagers went on to require surgical intervention. Judicious fluid management and watchful waiting were provided for the other children and teenagers who were treated conservatively.

Head and neck injuries, and neurological injuries were another indicator of severe injury. Among those with an
ISS $\geq 9,7(23.3 \%)$ had head or spinal injuries. The only case that died in our population was a boy where a soccer goal post had fallen on his head. He sustained an open basilar skull fracture and subarachnoid haemorrhage with multiple facial fractures. Trauma to the immature paediatric brain may result in disturbances in neuronal maturation and permanent damage to brain structure and function. ${ }^{39}$ Children and teenagers with head injuries have a higher rate of hospitalisation for close monitoring. ${ }^{40}$

Injuries to the upper and lower limbs were less likely to be associated with severe injuries. A large proportion 
(98.1\%) of these were either contusions or fractures that received intervention in the ED and then discharged on the same day. Similarly, for injuries to the back and spine, a large proportion (98.4\%) were strains or contusions which were managed conservatively with analgesia and sent home on the same day.

We identified several risk factors that will alert physicians of potential severe injuries when children and teenagers present to them with sports injuries. For such risk factors, there should be a lower threshold to involve a multidisciplinary team including orthopaedic, neurosurgical and trauma surgeons for timely investigation and resuscitation as required.

\section{Strengths and limitations}

We had a robust sample size of 10,951 patients in a large paediatric hospital in Singapore, providing data over 6 years for data analysis. The data come from a surveillance registry which mandates that circumstances of injury are detailed at the point of patient encounter in the ED. We recognise the limitations of a retrospective design of our study, which may give rise to incomplete data and inaccuracies that are difficult to verify. In this study on sports injuries, we were not able to detail the use of protective gear as the information was not routinely collected in the surveillance registry. Also, being a single-centre study, we recognise that our findings must be validated in other settings before they can be applied clinically.

\section{Conclusion}

Significant predictors for severe injuries included older age, injuries from rugby, injuries to the head and neck, abdomen and pelvis, fractures, dislocation, neurological injuries and transportation to ED by EMS. This study further alerts ED physicians to children and teenagers at risk of severe sports injuries.

\section{REFERENCES}

1. Toporek B. Survey: High school sports participation at all-time high, 23 August 2011. Available at: http://blogs.edweek.org/edweek/ schooled in_sports/2011/08/survey_high_school_sports_participation at_all-time_high.html. Accessed on 29 June 2020.

2. Maffulli N. Color Atlas and Text of Sports Medicine in Childhood and Adolescence. London: Mosby-Wolfe; 1995.

3. The Aspen Institute. Facts: Sports activity and children, 7 June 2018. Available at: www.aspenprojectplay.org/the-facts. Accessed on 29 June 2020.

4. The Aspen Institute. State of play: 2018. Available at: https://assets. aspeninstitute.org/content/uploads/2018/10/StateofPlay2018_ v4WEB 2-FINAL.pdf. Accessed on 29 June 2020.
5. Sports Singapore. Singapore's sports index key highlights 2015, 28 December 2019. Available at: https://www.sportsingapore. gov.sg/about-us/sports-particpation-in-singapore. Accessed on 16 August 2020.

6. Data.gov.sg/dataset. Sport participation level, 19 June 2020. Available at: https://data.gov.sg/dataset/sport-participation-level?view id=f822c2c2-8375-46ef-8fb6-32014867fd71\&resource id=dd403f4361ae-4d78-b63b-019b0bffa94f. Accessed on 16 August 2020.

7. Lystad RP, Curtis K, Browne GJ, et al. Incidence, costs, and temporal trends of sports injury-related hospitalisations in Australian children over a 10-year period: A nationwide population-based cohort study. J Sci Med Sport 2019;22:175-80.

8. Centers for Disease Control and Prevention (CDC). Nonfatal sportsand recreation-related injuries treated in emergency departmentsUnited States, July 2000-June 2001. MMWR Morb Mortal Wkly Rep 2002;51:736-40.

9. Theadom A, Mahon S, Hume P, et al. Incidence of sports-related traumatic brain injury of all severities: a systematic review. Neuroepidemiology 2020;54:192-9.

10. Caine D, Caine C, Maffulli N. Incidence and distribution of pediatric sport-related injuries. Clin J Sport Med 2006;16:500-13.

11. Darrow CJ, Collins CL, Yard EE, et al. Epidemiology of severe injuries among United States high school athletes: 2005-2007. Am J Sports Med 2009;37:1798-805.

12. Bayt DR, Bell TM. Trends in paediatric sports-related injuries presenting to US emergency departments, 2001-2013. Inj Prev 2016;22:361-4.

13. Burt CW, Overpeck MD. Emergency visits for sports-related injuries. Ann Emerg Med 2001;37:301-8.

14. Kim K-S, Park KJ, Lee J, et al. Injuries in national Olympic level judo athletes: an epidemiological study. Br J Sports Med 2015;49:1144

15. Lystad RP, Pollard H, Graham PL. Epidemiology of injuries in competition taekwondo: a meta-analysis of observational studies. J Sci Med Sport 2009;12:614-21.

16. Laoruengthana A, Poosamsai P, Fangsanau T, et al. The epidemiology of sports injury during the 37th Thailand National Games 2008 in Phitsanulok. J Med Assoc Thai 2009;92 Suppl 6:S204-10.

17. Maffulli N, Bundoc RC, Chan KM, et al. Paediatric sports injuries in Hong Kong: a seven year survey. Br J Sports Med 1996;30:218-21.

18. Choi DH, Song KJ, Shin SD, et al. Epidemiology and outcomes of sports-related traumatic brain injury in children. J Korean Med Sci 2019;34:e290

19. Stracciolini A, Casciano R, Levey Friedman H, et al. Pediatric sports injuries: an age comparison of children versus adolescents. Am J Sports Med 2013;41:1922-9.

20. Sam T. Auringer EYA. Common pediatric sports injuries. Semin Musculoskelet Radiol 1999;3:247-56.

21. Micheli LJ. Pediatric and adolescent sports injuries: recent trends. Exerc Sport Sci Rev 1987;14:359-74.

22. Brenner JS. Overuse injuries, overtraining, and burnout in child and adolescent athletes. Pediatrics 2007;119:1242-5.

23. Lau LL, Mahadev A, Hui JH. Common lower limb sport-related overuse injuries in young athletes Ann Acad Med Singap 2008;37:315-9. 
24. Walker SM, Casa DJ, Levreault ML, et al. Children participating in summer soccer camps are chronically dehydrated. Med Sci Sports Exerc 2004;36.

25. Schneuer FJ, Bell CJ, E Adams S, et al. The burden of hospitalized sports-related injuries in children: an Australian population-based study, 2005-2013. Inj Epidemiol 2018;5:45.

26. Caine D, Maffulli N, Caine C. Epidemiology of injury in child and adolescent sports: injury rates, risk factors, and prevention. Clin Sports Med 2008;27:19-50.

27. Steinberg L. Risk taking in adolescence: new perspectives from brain and behavioral science. Curr Dir Psychol Sci 2007;16:55-9.

28. Harmon KJ, Proescholdbell SK, Register-Mihalik J, et al. Characteristics of sports and recreation-related emergency department visits among school-age children and youth in North Carolina, 2010-2014. Inj Epidemiol 2018;5:23

29. Gallagher SS, Finison K, Guyer B, et al. The incidence of injuries among 87,000 Massachusetts children and adolescents: results of the 1980-81 statewide childhood injury prevention program surveillance system. J Burn Care Res 1986;7:363-4.

30. Zaricznyj B, Shattuck LJM, Mast TA, et al. Sports-related injuries in school-aged children. Am J Sports Med 1980;8:318-24.

31. Megat Azman MAA, Che Lan N, Hartini Azmi S, et al. A systematic review of type of injury among rugby union players. Singapore: Springer Singapore;2019.
32. Fuller CW, Taylor A, Kemp SPT, et al. Rugby world cup 2015: world rugby injury surveillance study. Br J Sports Med 2017;51:51-7.

33. Kaplan K, Goodwillie A, J Strauss E, et al. Rugby injuries: a review of concepts and current literature. Bull NYU Hosp Jt Dis 2008;66:86-93.

34. Pfister T, Pfister K, Hagel B, et al. The incidence of concussion in youth sports: a systematic review and meta-analysis. Br J Sports Med 2016;50:292-7.

35. Junge A, Cheung K, Edwards $\mathrm{T}$, et al. Injuries in youth amateur soccer and rugby players-comparison of incidence and characteristics. Br J Sports Med 2004;38:168-72.

36. Taylor BL, Attia MW. Sports-related injuries in children. Acad Emerg Med 2000;7:1376-82.

37. Wilson NC, Stott NS. Paediatric femoral fractures: factors influencing length of stay and readmission rate. Injury 2007;38:931-6.

38. Kang MS, Kim HS. Characteristics and trends of traumatic injuries in children visiting emergency departments in South Korea:A retrospective serial cross-sectional study using both nationwide-sample and singleinstitutional data. PLoS One 2019;14:e220798.

39. Anderson V, Catroppa C, Morse S, et al. Outcome from mild head injury in young children: a prospective study. J Clin Exp Neuropsychol 2001;23:705-17.

40. Werner C, Engelhard K. Pathophysiology of traumatic brain injury. Br J Anaesth 2007;99:4-9. 